\title{
How Natural a Kind Is "Eukaryote?"
}

\author{
W. Ford Doolittle \\ Department of Biochemistry and Molecular Biology, Dalhousie University, Halifax, Nova Scotia \\ B3H 4R2, Canada \\ Correspondence: ford@dal.ca
}

Systematics balances uneasily between realism and nominalism, uncommitted as to whether biological taxa are discoveries or inventions. If the former, they might be taken as natural kinds. I briefly review some philosophers' concepts of natural kinds and then argue that several of these apply well enough to "eukaryote." Although there are some sticky issues around genomic chimerism and when eukaryotes first appeared, if we allow for degrees in the naturalness of kinds, existing eukaryotes rank highly, higher than prokaryotes. Most biologists feel this intuitively: All I attempt to do here is provide some conceptual justification.

Gystematics biologists today often appear $\checkmark$ equivocal or confused about the reality of taxa in general, about whether they are inventions (constructs of the human mind) or discoveries (actually out there in the world). At the bottom and top of the Linnaean hierarchy, however, many biologists do see taxonomizing as a reality-driven discovery process. A group of them recently publicly endorsed the view that-even without any agreed on definition of "species" - one can calculate how many such entities there are on Earth and in the ocean (8.7 \pm 1.3 million) (Mora et al. 2011). And, more directly my subject here, the debate about whether living things are of two fundamental kinds (prokaryotes and eukaryotes) or three (bacteria, archaea, and eukarya (Wheelis et al. 1992) is conducted as if there were some fact of this matter, ascertainable by analyzing the data (Pace 2006). It is as if we thought, to quote Ian Hacking's apt description, that "There is a unique best taxonomy in terms of natural kinds, that represents nature as it is, and reflects the network of causal laws" (Hacking 1991, p. 111, emphasis mine).

Natural kinds, the recognizable cuts that are supposed to be arrayed on our plate when nature is "carved at the joints," have been variously conceived (or declared nonexistent) by philosophers starting with the ancient Greeks (Hacking 1991; Griffiths 1999; Campbell et al. 2011; Bird and Tobin 2012). Biologists cannot glibly propose to name and count kinds of organisms at any rank without committing themselves to some particular view as to what conception of "natural kind" they have in mind. My goal here is to provide my own admittedly incomplete catalog of some kinds of kinds that might be appropriate for systematists, and then to show how-in the case of "eukaryote" — we might use a mix of concepts, depending on our purposes. I will argue that the naturalness of kinds come in degrees, and by most standards "eukaryote" holds up well, although there are a

Editors: Patrick J. Keeling and Eugene V. Koonin

Additional Perspectives on The Origin and Evolution of Eukaryotes available at www.cshperspectives.org

Copyright (C) 2014 Cold Spring Harbor Laboratory Press; all rights reserved; doi: 10.1101/cshperspect.a015974

Cite this article as Cold Spring Harb Perspect Biol 2014;6:a015974 
W.F. Doolittle

few sticky issues. The naturalness of "prokaryote" is more problematic. Nevertheless, as I and Olga Zhaxybayeva have argued elsewhere (Doolittle and Zhaxybayeva 2013), the term is not as valueless as Norman Pace (Pace 2006) would hold.

\section{NATURAL KINDS BASED ON SHARED PROPERTIES}

Outside of biology, instances of a single natural kind are quite typically considered to share a unique trait or set of traits, common to all and only members of that kind. This essence (or essences) might be material or immaterial, as in Platonic ideals. Paradigm cases include the chemical elements, such as gold, whose essence is its atomic structure. Not only does this structure unambiguously identify instances of gold wherever and whenever they might be found, but many of gold's other properties follow from it. Gold found on Mars or in another universe would still be gold, and still be good for crowning human teeth.

An alternative to such essentialism, requiring no single universally shared property but a cluster of defining features, would be Richard Boyd's homeostatic property cluster (HPC) theory of natural kinds, seemingly quite appropriate to biology and the "species problem" in particular (Boyd 1999). HPC kinds share traits, but no single trait (no single property of the cluster) is necessary in all cases. Most dogs have four legs and a tail, but three-legged tail-less individuals might still be dogs if they bark and chase cats. Although no single property is necessary or sufficient to distinguish members of an HPC kind, an underlying "homeostatic causal mechanism(s)" ensures cohesiveness, continuity, and, generally, considerable overlap in properties between individuals. For dogs the homeostatic mechanism(s) would be a shared gene pool, environmental constraints, and developmental program. Although this may sound suspiciously like an essence, the emphasis is on processes not properties, and causal mechanisms and the HPC kinds they maintain can, like species, evolve.

Natural kinds are what laws of nature are supposed to be about and it is often held that one cannot have a science of laws without them. Griffiths (1999) provides an appealingly minimalist criterion based on this presumption, which permits degrees of "naturalness."

A kind is (minimally) natural if is possible to make better than chance predictions about the properties of its instances. Surprisingly, this utterly minimal conception of a natural kind is not toothless. It does not license the conclusion that any way of classifying nature is as good as any other. Natural kinds are ways of classifying the world that correspond to some structure inherent in the subject matter being classified (Griffiths 1999, p. 216).

There is no "unique best taxonomy" with kinds of this sort, and it is possible that an individual can belong to several such kinds. But, Griffiths explains:

Even if different categories are valuable for different purposes, it is still true that some are better for a particular purpose than others and that some have no foreseeable use at all. Embodying these ideas in the language of natural kinds links it to a broadly realist perspective in which the predictive and explanatory value of categories is taken to be prima facie evidence that they capture part of the structure of the world (Griffiths 1999, p. 217).

After an accounting of historical natural kinds, which most biologists after Darwin consider all taxa minimally to be, I will present some arguments in favor of "eukaryote" as a natural kind for many "particular purposes."

\section{NATURAL KINDS BASED ON SHARED HISTORY}

Many have claimed that preDarwinian classification was essentialistic, most famously Ernst Mayr (1982), who called such thinking typological, linked it to Platonism and deemed it antithetical to the acceptance of evolution, which he argued entails "population thinking." Similarly, the philosopher David Hull (1965a,b) blamed "two thousand years of stasis," which in his view still stultifies systematics, on Aristotelian essentialism. Although there is considerable contemporary scholarly disagreement about just how enthusiastically wedded pre-Darwinian systematists were to ancient Greek philosophy (Winsor 
2006; McOuat 2009), there is no doubt that The Origin of Species changed the game, whatever it had been. Darwin wrote:

... that the characters which naturalists consider as showing true affinity between any two or more species, are those which have been inherited from a common parent, all true classification being genealogical; - that community of descent is the hidden bond which naturalists have been unconsciously seeking, and not some unknown plan of creation, or the enunciation of general propositions, and the mere putting together and separating objects more or less alike (Darwin 1859 , p. 420).

In Darwinian biology, it is only common descent that comprises the essence uniting organisms of the same kind. Essences do not inhere in individuals or taxa themselves but in the pattern of (cladistic) relationships between them, and are historical rather than material or even ideal (in Plato's sense) in character. Any living creature born of dogs would be a dog even if it has none of the cluster of properties by which dogs might be recognized as an HPC species. Conversely, any cat surgically modified to show all those properties would still not be a dog.

However, because progeny without surgical intervention generally resemble parents, phenetic classifications (based only on shared properties) are often good proxies for cladistic branching relationships. In an important sense, Darwin's first profound and revolutionary contribution to biology was thus to legitimize phenetic classification by providing a theoretical basis for its frequent success. His theory liberates taxonomy from creationist essentialism ("some unknown plan of creation") and elevates it above nominalism ("the mere putting together and separating objects more or less alike") because a tree-like pattern of lineage splittings underwrites the tree-like classification of "groups subordinate to groups."

Panchen (1992) nicely emphasizes the centrality of this linkage of phenetics and phylogenetics in his Classification, Evolution and the Nature of Biology. He recounts his beginning students' inability to answer the question "What is the theory of evolution?"
... students cannot characterize the theory of evolution. Admittedly, some will give a (usually erroneous) account of the theory of Natural Selection, which they will associate (correctly) with the name of Charles Darwin and, much less often, also that of Alfred Russel Walllace. Natural selection is one component of evolutionary theory as proposed by Darwin and Wallace, but the other, for which selection is merely a hypothesis of mechanism, is the theory that evolution has occurred. But that theory must have been proposed to explain some body of data and/or lower level theories. What I wanted to hear from my students was what that corpus of knowledge was. The answer, as we have seen, is that the theory of evolution states that the apparent relationships of organisms in a systematic classification are real relationships, because "relationship" in such a context is not a metaphor but is actually to be ascribed to community of descent. Thus the theory of evolution was proposed by Darwin and Wallace to explain the pattern of relationships in what we may now term "Natural Classification” (Panchen 1992, p. 3).

Such historical or genealogical essentialism unfortunately tells us nothing about taxonomic rank, however, only relationships. Darwin recognized the arbitrariness of distinctions between strains, species, and genera, whereas higher taxa were understood to be man-made categories by Linnaeus and others even before 1859 (Ereshefsky 1999). So, whereas shared properties might identify Lepidoptera as a natural kind sharing a common developmental program or some more abstract moth-butterfly essence, historical essentialism remains uncommitted about the boundaries and reality of such higher groups.

\section{THE SPECIAL CASES OF SPECIES AND DOMAINS}

Mayr's biological species concept (BSC) can be seen as an attempt to overcome the ranking problem, for that taxonomic level (Mayr 1982). Species are the most inclusive grouping of genealogically related individuals capable of forming an interbreeding population, according to the BSC. At the level of gene genealogy this would normally entail that phylogenetic trees for different genes sampled from within a species would be different, while trees for such 
W.F. Doolittle

genes sampled from different species would be the same-a criterion that has been used to extend the BSC into prokaryotic systematics, where "interbreeding" has quite a different character, but recombination can be rampant (Dykhuizen and Green 1991).

The "species" category or kind defined in this way seems to me a natural enough one, certainly by Griffiths' criteria and maybe even for essentialists, the essence being just that sort of interbreeding population genetic behavior. One might find species on Mars or in another universe. But that does not mean that particular species taxa (Canis familiaris or Homo sapiens, for instance) have distinct and permanent individual essences that make them distinct enduring natural kinds (like gold), as would be consistent with "typological thinking." Indeed, it means that they do not: $C$. familiaris and $H$. sapiens are just particular instantiations or individuals of the BSC natural kind, and we would not expect to find them on Mars. Nor does it mean that all organisms, many of which seldom if ever "interbreed," must belong to a species. So BSC-defined species cannot play a reliably general role as the fundamental unit of systematics.

Hull (1978) and Michael Ghiselin (1974) have made much of the notion that particular species are, indeed, spatiotemporally bounded individuals, like you or me. Ghiselin wrote:

Traditionally, species (like other taxa) have been treated as classes (universals). In fact they may be considered individuals (particular things). The logical term "individual" has been confused with a biological synonym for "organism.” If species are individuals, then: (1) their names are proper, (2) there cannot be instances of them, (3) they do not have defining properties (intensions), and (4) their constituent organisms are parts, not members. "Species" may be defined as the most extensive units in the natural economy such that reproductive competition occurs among their parts (Ghiselin 1974, p. 536).

Even asexual organisms outside the scope of the BSC can form species such that "reproductive competition occurs among the parts" - indeed something like this has been used to define species for prokaryotes that do not recombine (Co- han 2002). So in this formulation we might take individual taxa as real, but they are still not property-based, gold-like, natural kinds. Martians, even if they looked exactly like us or our dogs, would not be $H$. sapiens or $C$. familiaris unless descended from human colonists and their companion animals.

But, again, neither the BSC nor treating taxa as individuals will help us to delimit taxa higher than species. The component members of higher taxa do not interbreed nor can they be construed as reproductively competing parts in the same way. Only phenetic criteria and some presumptions about their relative fundamentalness can be used to cut horizontally across the treelike pattern of descent relating species to delimit genera, families, orders and on up. It is widely understood that such rankings are endlessly arguable and not comparable across groups, and there is no causal story invoking a genus or higher taxon that is not in fact a story about some or all of its constituent species. Devitt, using something like Griffiths' minimal conception, concludes that "although the higher categories may have some practical value, they are doing no explanatory work: they are not natural kinds" (Devitt 2011, p. 167).

An exception could be made for the very highest taxa, but in a different way than in the case of species. If the Tree of Life were an unreticulated pattern of bifurcations all the way down to a single last common ancestor, then its deepest division (its earliest bifurcation) would unambiguously separate all life into two Darwinian (historical) natural kinds ("domains" if you will), an indisputable fact however we might chose to rank the subsequent bifurcations along either of the two branches.

\section{THREE DOMAINS VERSUS TWO}

This unavoidable logic notwithstanding, the 1977 publication by Woese and Fox argued for the view that Life comprises three basic types of organisms-bacteria, archaea, and eukaryawhich they then called "urkingdoms." Although at that time admitting the possibility that "One of the three may represent a far earlier bifurcation than the other two, making there in effect 
only two urkingdoms" (Woese and Fox 1977, p. 5089, emphasis mine), these authors soon developed the notion that the last common ancestor was not a single cell or species, but a population of entities quite different from any contemporary cell, called collectively "the progenote” (Woese 1982). Thus Woese (1998) would write some 20 years later that:

Organismal lineages, and so organisms as we know them, did not exist at these early stages. The universal phylogenetic tree, therefore, is not an organismal tree at its base but gradually becomes one as its peripheral branchings emerge. The universal ancestor is not a discrete entity. It is, rather, a diverse community of cells that survives and evolves as a biological unit. This communal ancestor has a physical history but not a genealogical one. Over time, this ancestor refined into a smaller number of increasingly complex cell types with the ancestors of the three primary groupings of organisms arising as a result.

This model of common ancestry without a common ancestor seems to license the claim for a tripartite living world, but does so by stepping outside of the Darwinian systematic framework ("all true classification being genealogical”). It is also strikingly inconsistent with the usual presentation of the universal tree by Woese and colleagues, which does indeed display bacteria as an "earlier branching than the other two."

Such ambivalence undermines Pace's (2006) arguments against the use of the term "prokaryote." On the one hand, Pace argues in an influential Nature opinion piece, prokaryotes are paraphyletic (eukaryotes having arisen from within them) and thus not a legitimate taxon. On the other, he holds that eukaryotes did not arise from prokaryotes, because their last common ancestor was neither, but rather "the progenote."

Much of what is at issue here is a conflict between recognizing natural kinds based on shared properties (phenetics) versus natural kinds based on shared history (phylogenetics). Without doubt, Stanier and van Niel, to whose 1962 paper the widespread use of "prokaryotes" and "eukaryotes" and the belief that any or- ganism must be one or the other can be traced, understood the dichotomy to be based on shared properties. Most famously, the former wrote in a magisterial textbook, that:

... this basic divergence in cellular structure, which separates the bacteria and blue-green algae from all other cellular organisms [eukaryotes], represents the greatest single evolutionary discontinuity to be found in the present day world (Stanier et al. 1963, p. 85).

It was in fact mostly (and problematically) the shared lack by bacteria and blue-green algae of the properties thought to be common to all and every cell of the eukaryotic natural kind that defined prokaryotes for Stanier and van Niel, although now we might also include several more positive discriminators (Martin and Koonin 2006). Whether Stanier and van Niel understood the "evolutionary discontinuity" to be phylogenetic as well as phenetic is unclear and unlikely, although this is what Pace (and Woese before him) charges them with. Most likely Stanier and van Niel actually thought, as did most of their contemporaries, that more complex cells of the eukaryote kind arose somehow from some particular lineage(s) of prokaryotes, making the latter paraphyletic, but not polyphyletic. The deepest phylogenetic gap would thus have separated prokaryotes into two prokaryotic clades, as indeed Pace's three domain tree actually shows (Pace 2006).

The conflation of phenetic, or propertybased, and phylogenetic, history-based, conceptions of natural kinds was made very clear in a noisy debate between Woese (1998) and Mayr (1998) played out in the pages of the Proceedings of the National Academy of Sciences. The latter, while accepting the former's threedomain tree in which archaea and eukarya are sisters, nevertheless insisted that those "basic divergences" in cell structure that separated eukaryotes from either bacteria or archaea were many and important, whereas those separating bacteria and archaea were (relatively) fewer and less consequential. So a "natural classification" taking into account "degree of difference" as well as evolutionary branching pattern would retain the prokaryote/eukaryote dichotomy, he 
W.F. Doolittle

held. Mayr called such a classification "evolutionary" or "Darwinian" because relationships within it remain strictly genealogical (polyphyletic groups are not allowed); but naming and ranking of taxa may take phenetic similarity and cohesion into account.

Although scholars may disagree on this ( $\mathrm{Pa}-$ dian 1999; Wilkins 2009), the following passage from The Origin seems to indicate that Darwin would indeed concur with such an approach:

I believe that the arrangement of the groups within each class, in due subordination and relation to each other, must be strictly genealogical in order to be natural; but that the amount of difference in the several branches or groups, though allied in the same degree in blood to their common progenitor, may differ greatly, being due to the different degrees of modification which they have undergone; and this is expressed by the forms being ranked under different genera, families, sections, or orders (Darwin 1859, p. 369).

Woese (1998), in vigorous rebuttal of Mayr (1998), asserted that the latter gave too little attention to the degree of phenetic difference between bacteria and archaea. Moreover, although admitting that "a phylogenetic tree based upon the molecular data shows that the newly recognized domain, the archaea, is, if anything, more closely related to eukaryotes than to the familiar bacteria" (Woese 1998, p. 1104), Woese would not accept the cladistic implication of this finding, that there are "in effect only two urkingdoms," one bacterial and the other archaeal plus eukaryotic.

Thus, this Battle of the Titans was about (1) degrees of "degrees of difference," a subjective matter, and (2) the practice of systematics, a sociophilosophical one. Or put another way, it was about different kinds of natural kinds, and which is best. One way of carving nature at the joints, based on properties (cell structure), arguably gives us prokaryotes and eukaryotes. Another, historical/genealogical in focus, yields bacteria and a second domain comprising archaea plus eukarya. Neither unambiguously gives us three domains.

It may be that some unbiased jury could decide that the phenetic distinction between bacteria and archaea is at least as "significant" as that between prokaryotes and eukaryotes and rule for the three-domain perspective on such strictly phenetic grounds. Although historical kinds are de rigueur in post-Darwinian practice, there is no principle by which they can claim exclusive representation of "nature as it is." But jury bias would be difficult to eliminate; some might insist that components of the translation machinery should receive extra weight in phenetic analyses, some might favor cellular ultrastructure, and still others would argue that an "all-traits-are-equal" approach is more fairminded. Disputes in systematics are arguments about what should be done masquerading as competing claims about what is.

\section{THE EUKARYOTE KIND}

Still, what was not in dispute between Mayr and Woese and Pace was the monophyly and phenotypic cohesion of extant eukaryotes, a natural kind on several counts. We should consider these before discussing the problematics.

Woese's writings often made him sound like a born-again pre-Darwinian "typological thinker" of the sort of which Mayr wished to rid the discipline.

Twenty-first century biology will concern itself with the great "nonreductionist" 19th century biological problems that molecular biology left untouched. All of these problems are different aspects of one of the great problems in all of science, namely, the nature of (complex) organization. Evolution represents its dynamic, generative aspect; morphology and morphogenesis represent its emergent, material aspect. One can already see the problem of the evolution of cellular organization coming to the fore. And because of both its pressing practical and its fundamental nature, the problem of the basic structure of the biosphere is doing so as well.... My own career is one of the links between biology's reductionist molecular past and its holistic future (Woese 2004, p. 176).

Most certainly, the Woese school's focus on ribosomal RNA and secondarily on other components of the translational and transcriptional machinery as telling the true evolutionary story has an essentialist ring. The accepted position of any species on the Tree of Life is that dictated by 
these components, even if the majority of its genome would put it elsewhere. For many microbiologists, natural classification (to the extent systematics concerns them) is rRNA phylogenetics.

It seems unsurprising that Woese and early adapters of his methodology (myself included) were for the most part trained as molecular biologists, predisposed to see genes involved in replication, transcription, and translation as an organism's most fundamental and important. It may well be that many of these genes are less frequently transferred than others, but the reasons are more likely to be high rates of expression and "connectivity" (Cohen et al. 2011; Park and Zhang 2012) than their fundamental roles. And it is true that no species defined as eukaryotic by rRNA sequence has been considered prokaryotic on other grounds.

Something more like HPC natural kind status has also been invoked for eukaryotes, at least since Stanier and van Niel's 1962 manifesto and likely before Sapp (2009). Nowadays, properties thought to characterize all or most eukaryotes and no or only a few prokaryotes are numerous. Indeed, one of the fruits of comparative genomics is the discovery (or at least the commonly held belief) that many of the complex cellular structures of contemporary eukaryotes were likely present in LECA (the last eukaryotic common ancestor). Koumandou et al. (2013), for instance, recently conclude that:

It is now clear that the LECA was both a flagellate and capable of movement by actin-based pseudopodia and possessed a sophisticated cytoskeleton, including large families of kinesin and dynein motors. It possessed a complex and likely very flexible, metabolism and a fully functional mitochondrion. Endomembrane compartments would have been essentially indistinguishable from modern cells, and included the endoplasmic reticulum, the Golgi complex, endosomes, autophagosomes and others. ... The LECA was also capable of both conventional endocytosis and phagocytosis. The nucleus was fully differentiated with nuclear pore complexes and a sophisticated system for organization and regulation of chromatin. A high energy burden is clearly implied by this architecture and required to construct and maintain these compartments and systems plus a differentiated cytoskeleton to coordinate location and function. Heterochromatin in some form could also support life-cycle and/or environmental cue-dependent coordinate gene expression. LECA also supported meiosis.

Some extant lineages lack some of these features, for instance, "fully functional mitochondria," but this is fully consonant with being an HPC kind. And the interactions of eukaryotic mobility, compartmentalization, and membrane trafficking systems seem sufficient to establish a "homeostatic causal mechanism."

Some investigators, by attributing to LECA all those properties present in some substantial fraction of its surviving descendants, are forced to infer an ancestor with substantially more capabilities than all or most of these descendants, so that the history of post-LECA eukaryotic lineages is one of specialization and differential loss. For example, Harish et al. (2013) describe a non-Woesian three-domain tree (bacteria and archaea being sisters) in which the last common ancestral eukaryote and prokaryote boast more protein superfamilies (SFs) than their typical descendant lineages, and the "most recent" (i.e., "last") universal common ancestor (MRUCA or LUCA) carried even more still. These researchers elaborate a remarkably Velikovskian scenario around this notion.

MRUCA, identified as the root of the modern crown of global phylogeny, features an unexpectedly complex genome that defies characterization as a primitive ur-cell such as the progenote of Woese. Thus, it seems inconceivable to us that an ancestral proteome containing three fourths of all SFs in the modern crown can be identified with the proteome of the ur-ancestor, i.e. the first cell and the root of Earth's first phylogenetic tree. Accordingly, we suggest that the modern crown is a re-diversified tree rooted in complex survivors of mass extinction events that occurred some time before the Cambrian radiation.... In other words, the modern crown is the most recent in a series of two or more global radiations that produced diverse biota from bottlenecked populations that arose in the wake of mass extinctions ... MRUCA[,] the seed of the modern crown in this interpretation[,] would be the survivor of a mass extinction that laid waste and 
W.F. Doolittle

bottlenecked an earlier crown population. In this scenario MRUCA is a unicellular or a multicellular survivor of a global collapse of the environment due to extreme climate change (Harish et al. 2013, pp. 1602-1603).

The more prosaic alternative, in my view much more consistent with the principle of uniformitarianism beloved of Darwin, is to recognize that lateral gene transfer (LGT) allows descendant lineages of a single ancestral entity (cell or species) to harbor many genes not present in that ancestor. This ancestor (which need in principle have borne no genes directly ancestral to any in circulation today) would not be recognized as unusual in the size or complexity of its genome, were it still alive. This scenario is uniformitarian in that it assumes that cells and the evolutionary forces affecting them (in particular, LGT) were not unlike what we observe now, as far back in time as we can know. The pools of genes shared through LGT by prokaryotes and (at lower frequency) unicellular eukaryotes, occasionally overlapping but generally kept distinct by barriers to gene expression (e.g., incompatible transcriptional and translational signals and introns), would be important "homeostatic causal mechanisms."

This complication aside, there seems little expressed doubt in the literature that LECA was a single species that would now be considered eukaryotic on phenetic grounds (as above) and few (although some, quite idiosyncratic, like Harish et al. 2013) suggestions that any species we now consider prokaryotic derives from it. In particular, if we take possession of mitochondria with genomes reduced by loss and EGT as a sure sign of eukaryoteness, and the fact that all extant mitochondria and mitochondrion-derived organelles likely derive from a single last common mitochondrial ancestor whose genome was already reduced by $\sim 90 \%$ (Gray et al. 1999), LECA was already a eukaryote. That is to say, post-LECA eukaryotes are monophyletic and "holophyletic" (not paraphyletic) (see Ashlock 1974). That they might be initially chimeric (the product of some bacterial-archaeal "fusion") would not alter such a claim for monophyly, although separate infusions of foreign genes (as in the plastid endo- symbiosis affecting only part of the eukaryotes; see below) might.

Thus, eukaryotes appear to be natural kinds on the basis of shared properties and shared history. Moreover, by Griffiths' looser criteria, that the "predictive and explanatory value of categories is taken to be prima facie evidence that they capture part of the structure of the world," eukaryotes pass the test. Even with the most prokaryote-like eukaryotes of which I am aware, the microsporidia (highly derived fungi), the safest assumption for any unknown property would be that it is "eukaryotic" in character (Corradi and Selman 2013). Prokaryotes, if the rooted three-domain tree is accepted and paraphyly eschewed, are natural only in the first way (shared properties, or, worse, shared lack of eukaryotic characteristics), and arguably designating a species as prokaryotic has weaker "predictive and explanatory value," although such value is hard to quantify or compare.

\section{STICKY ISSUES}

I see two flies in the eukaryote-as-natural-kind ointment. The first is genomic chimerism-not that which some have argued gave rise to the very first cell we might want to consider eukaryotic (called the "FECA" by some) (Wilson and Dawson 2011) - but that which was created by organellar endosymbiosis and EGT, as well as LGT from subsequently disappeared endosymbionts and mere prokaryotic food. An early decision by Woese and colleagues to consider nuclear-encoded 18S, not organellar 16S rRNA, as properly representing eukaryotes in the universal Tree of Life was not at the time questioned. Woese and Fox (1977) wrote:

If there had been an "engulfing species" in relation to which all the other organisms were endosymbionts, then it seems likely that $18 \mathrm{~S}$ rRNA represents that species. This hypothetical group of organisms, in one sense the major ancestors of eukaryotic cells, might appropriately be called urkaryotes. Detailed study of anaerobic amoebae and the like, which seem not to contain mitochondria and in general are cytologically simpler than customary examples of eukaryotes, might help to resolve this question (Woese and Fox 1977, p. 5089). 
Assumed here are (1) that it is the host and not the hosted whose history should be taken as that of the eukaryotic lineage; (2) that "urkaryotic" organisms that never had mitochondria but that we would want to call eukaryotes on other grounds (Cavalier-Smith's 1983 archezoa) once existed and might still be around to serve as support for this notion; and (3) implicitly but surely in the back of all our minds in the late 1970s, that the genetic contribution of mitochondria or plastids - that fraction of any eukaryote's genome comprising genes of organellar origin (either still organellar or now nuclear)—was small. We now know assumptions 2 and 3 to be problematic if not clearly false, but taking 18S rRNA (and associated translational machinery) as the proper trackers of eukaryote phylogeny remains unquestioned.

The apparent falseness of 2 was a surprise. In a history many times recounted, CavalierSmith's notion that certain amitochondriate anaerobic eukaryotes (archezoa) that fortuitously branched low in relatively unsophisticated phylogenetic analyses were primitively without organelles held great appeal (Cavalier-Smith 1983). It was consonant with what was then the standard version of the endosymbiont hypothesis, which imagined that phagocytosis and the associated complexities of eukaryotic cell structure preceded the acquisition of mitochondria. But now, all examined eukaryotes prove to harbor mitochondria or "mitochondrion-related organelles," sometimes highly derived (e.g., lacking DNA) and often engaged in activities other than respiration (Gray 2012). We may never find any living "archezoa," and one could at least imagine constructing a tree including all known eukaryotes from various mitochondrion-derived gene sequences rather than nuclear genes. Such a tree might be rooted in the proteobacteria, not as sister to archaea. Support for this approach could come from the fact that, contrary to assumption 3 above, the majority of eukaryotic genes that can be shown to have prokaryotic homologs find these homologs in the bacteria, not archaea, the presumed prokaryotic sisters (or ancestors) of the "host" lineage (e.g., Pisani et al. 2007). Such genes are not necessarily of organellar origin; the point is that they are not archaeal.

Cotton and McInerney (2010), while again finding that bacteria-similar genes outnumber archaea-similar genes by more than four to one (in yeast), nevertheless note that the:

$\ldots$ archaebacterium-derived genes are significantly more likely to be essential to yeast viability, are more highly expressed, and are significantly more highly connected and more central in the yeast protein interaction network ...

and thus argue that:

... genes of archaebacterial origin are in some senses more important to yeast metabolism than genes of eubacterial origin. This importance reflects these genes' origin as the ancestral nuclear component of the eukaryotic genome (Cotton and McInerney 2010, p. 17252).

This would no doubt be the common feeling, and the accepted structure of the three-domain tree remains the most popular. My point is that whether or not we root eukaryotes with archaea or in proteobacteria is a judgment call, intimately tied up with prevailing theories about the origins of eukaryotes, and certain prejudices about the importance of hosts over symbionts. It is not a discoverable fact!

In any case, if mitochondria were already established in LECA, where we root eukaryotes does not impinge on their claim to monophyly. What might impinge is the subsequent incursion into only part of the eukaryote clade, of plastids. An earlier paper from McInerney's group (Pisani et al. 2007) concludes that:

\begin{abstract}
... there are three distinct phylogenetic signals in eukaryotic genomes. In order of strength, these link eukaryotes with the Cyanobacteria, the Proteobacteria, and the Thermoplasmatales, an archaebacterial (euryarchaeotes) group. These signals correspond to distinct symbiotic partners involved in eukaryote evolution: plastids, mitochondria, and the elusive host lineage ... (Pisani et al. 2007, p. 1752).
\end{abstract}

It would be surprising if a preponderance of cyanobacterial genes characterized all eukaryotes, even those with no plastids in their history (indeed, see Koonin 2010). But quite possibly a Tree of Life displaying eukaryotes according to the majority of their genes, not just those 
W.F. Doolittle

deemed "most important," would show them to be polyphyletic, some grouping with proteobacteria and some with cyanobacteria. Again, that we do not make trees in this way is a choice based on theories about origins and notions of relative importance, contingencies of the history of our discipline and not unarguable facts of nature.

The second fly in the ointment is built into the notion of eukaryogenesis: that eukaryotes must have arisen from some thing or things that were not eukaryotes. There are at least four ways of thinking about this, and they can be variously parsed (O’Malley 2010; Forterre 2011; Koumandou et al. 2013). First, one might assume that the many eukaryotic peculiarities arose slowly and sequentially, perhaps driven by the advantages of phagocytosis, so that most were in place before the acquisition of mitochondria. Unfortunately, either by bad luck or because of mass extinctions and bottlenecks, none of the intermediate stages have left survivors (the hapless "archezoa"). Second, one might suppose that mitochondria were acquired first (prokaryotes with endosymbiotic prokaryotes are now known) (Husnik et al. 2013), and all the complexities of eukaryoteness were then rapidly developed secondary accommodations to this great evolutionary advance (Lane and Martin 2010). Third, although a bacterial/ archaeal syntrophy is, indeed, the basis of eukaryogenesis, integration into a single cellular entity/lineage was mutualistic, and not as imagined in traditional endosymbiosis theory. The "Hydrogen Hypothesis" is an example (Martin and Müller 1998). Fourth, the eukaryotic lineage is actually the oldest. Thus, the fact that many eukaryotic genes are very dissimilar to homologous prokaryotic genes does not reflect rapid evolution leading up to or following the development of phagocytosis and the acquisition of mitochondria, but rather ancient divergence (before the bacterial/archaeal split) (e.g., Sogin 1991).

Why eukaryogenesis is a problem is that whichever of these four scenarios we adopt, there will be an uncoupling, more or less sudden, between "eukaryote" as defined by shared properties and "eukaryote" as defined histori- cally with whichever lineage of genes we think tracks that history. Extant eukaryotes may be a good enough natural kind (as I will conclude momentarily), but we do not really have a principled way of deciding when the kind first appeared on Earth. To be sure, molecular and cellular paleontologists make various claims about when eukaryotic cells or eukaryotic metabolites first appear in the fossil record, and those brave enough to put dates on gene trees also have such opinions. But they are using different diagnostics and definitions of "eukaryoteness" between which there can be no principled reconciliation.

\section{"EUKARYOTE" IS A QUITE GOOD NATURAL KIND, "PROKARYOTE" LESS SO}

Existing eukaryotes nevertheless might be taken as natural kinds of any of the several general sorts sketched at the beginning of this essay. If one must have essences, the translational machinery seems to provide that. Indeed, it was the clear distinction between eukaryotic and prokaryotic ribosomal RNAs that first convinced biologists that the endosymbiont theory for organelle origins was correct. As "homeostatic property clusters," the collection of eukaryotespecific molecular machinery that phylogenomic reconstruction assigns to LECA is extensive and bespeaks a community of integrated cellular processes serving a limited range of energy metabolisms. As historical kinds they appear monophyletic, at least as their history is now traced. Most importantly, the causal coupling of phenetic similarity and phylogenetic relatedness that is foundational for Darwin's theory of evolution holds up well. That is, as Panchen put it: "apparent relationships of organisms in a systematic classification are real relationships." And, because of this, "eukaryote" readily meets Griffiths' criteria as a way of "classifying the world that correspond[s] to some structure inherent in the subject matter being classified."

Pace (2006) is right that "prokaryote" describes a less satisfactory natural kind. Even if considered monophyletic, prokaryotes are not holophyletic. If the translational machinery is taken as essence-defining, they fall apart: Ar- 
chaea are indeed closer to eukaryotes. As homeostatic property clusters, they would still be recognized more for the numerous eukaryotespecific features they all lack than the prokaryotic-specific features they all share. However, the prokaryote/eukaryote distinction was drawn with cell structure and likely genomic simplicity, not phylogenetic relationships, in mind. The kind "prokaryote" remains of use in that regard (Doolittle and Zhaxybayeva 2013). In many areas of cell and especially molecular biology, it is still "possible to make better than chance predictions about the properties of its instances," Griffiths' minimal criterion. There is much to be gained in biology, I think, by allowing naturalness of kinds to come in degrees.

\section{ACKNOWLEDGMENTS}

I thank Maureen O’Malley for critical comments on this essay.

\section{REFERENCES}

Ashlock PD. 1974. The uses of cladistics. Ann Rev Ecol Systematics 5: 81-99.

Bird A, Tobin E. 2012. Natural kinds. In The Stanford encyclopedia of philosophy, Winter 2012 ed. (ed. Zalta EN). Stanford University Press, Stanford, CA.

Boyd R. 1999. Homeostasis, species, and higher taxa. In Species: New interdisciplinary essays (ed. Wilson RA), pp. 141-185. MIT Press, Cambridge, MA.

Campbell JK, O’Rourke M, Slater M. 2011. Carving nature at its joints: Natural kinds in metaphysics and science (topics in contemporary philosophy). MIT Press, Cambridge, MA.

Cavalier-Smith T. 1983. A revised six-kingdom system of life. Biol Rev Camb Philos Soc 73: 203-266.

Cohan FM. 2002. What are bacterial species? Annu Rev Microbiol 56: 457-487.

Cohen O, Gophna U, Pupko T. 2011. The complexity hypothesis revisited: Connectivity rather than function constitutes a barrier to horizontal gene transfer. $\mathrm{Mol}$ Biol Evol 28: 1481-1489.

Corradi N, Selman M. 2013. Latest progress in microsporodian genome research. J Eukaryot Microbiol 60: 309-312.

Cotton JA, McInerney JO. 2010. Eukaryotic genes of archaebacterial origin are more important than the more numerous eubacterial genes, irrespective of function. Proc Natl Acad Sci 107: 17252-17255.

Darwin CR. 1859. On the origin of species by means of natural selection, or the preservation of favoured races in the struggle for life, 1st ed. J. Murray, London.

Devitt M. 2011. Natural kinds and biological realisms. In Carving Nature at its joints: Natural kinds in metaphysics and science (topics in contemporary philosophy) (ed. Campbell JK, et al.), pp. 155-173. MIT Press, Cambridge, MA.

Doolittle WF, Zhaxybayeva O. 2013. What is a prokaryote? In The prokaryotes-Prokaryotic biology and symbiotic associations (ed. Rosenberg E, et al.), pp. 41-58. Springer, Berlin.

Dykhuizen DE, Green L. 1991. Recombination in Escherichia coli and the definition of biological species. J Bacteriol 173: 7257-7268.

Ereshefsky M. 1999. Species and the Linnaean hierarchy. In Species: New interdisciplinary essays (ed. Wilson RA), pp. 285-306. MIT Press, Cambridge, MA.

Forterre P. 2011. A new fusion hypothesis for the origin of Eukarya: Better than previous ones, but probably also wrong. Res Microbiol 162: 77-91.

Ghiselin MT. 1974. A radical solution to the species problem. Systematic Biol 23: 536-544.

Gray MW. 2012. Mitochondrial evolution. Cold Spring Harb Perspect Biol 4: a011403.

Gray MW, Burger G, Lang BF. 1999. Mitochondrial evolution. Science 283: 1476-1481.

Griffiths PE. 1999. Squaring the circle: Natural kinds with historical essences. In Species: New interdisciplinary essays (ed. Wilson RA), pp. 208-228. MIT Press, Cambridge MA.

Hacking I. 1991. A tradition of natural kinds. Philos Stud 61: 109-126.

Harish A, Tunlid A, Kurland GC. 2013. Rooted phylogeny of the three superkingdoms. Biochimie 95: 1593-1604.

Hull D. 1965a. The effect of essentialism on taxonomy: Two thousand years of stasis (I). Br J Philos Sci 15: 314-326.

Hull D. 1965b. The effect of essentialism on taxonomy: Two thousand years of stasis (II). Br J Philos Sci 16: 1-18.

Hull D. 1978. A matter of individuality. Philos Sci 45: 335360.

Husnik F, Nikoh N, Koga R, Ross L, Duncan RP, Fujie M, Tanaka M, Satoh N, Bachtrog D, Wilson AC, et al. 2013. Horizontal gene transfer from diverse bacteria to an insect genome enables a tripartite nested mealybug symbiosis. Cell 153: 1567-1578.

Koonin EV. 2010. The origin and early evolution of eukaryotes in the light of phylogenomics. Genome Biol 11: 209.

Koumandou VL, Wickstead B, Ginger M, van der Giezen M, Dacks JB, Fiekd MC. 2013. Molecular paleontology and complexity in the last eukaryotic common ancestor. Crit Rev Biochem Mol Biol 48: 373-396.

Lane N, Martin W. 2010. The energetics of genome complexity. Nature 467: 929-934.

Martin W, Koonin EV. 2006. A positive definition of prokaryotes. Nature 442: 868.

Martin W, Müller M. 1998. The hydrogen hypothesis for the first eukaryote. Nature 392: 37-41.

Mayr E. 1982. The growth of biological thought. Harvard University Press, Cambridge, MA.

Mayr E. 1998. Two empires or three? Proc Natl Acad Sci 95: 9720-9723.

McOuat G. 2009. The origins of "natural kinds": Keeping "essentialism" at bay in the Age of Reform. Intellectual Hist Rev 19: 211-230. 
W.F. Doolittle

Mora C, Tittensor DP, Adl S, Simpson AG, Worm B. 2011 How many species are there on Earth and in the ocean? PLoS Biol 9: e1001127.

O’Malley MA. 2010. The first eukaryotic cell: An unfinished history of contestation. Stud Hist Philo Biol Biomed Sci 41: $212-224$.

Pace NR. 2006. Time for a change. Nature 441: 289.

Padian K. 1999. Charles Darwin's view of classification in theory and practice. Syst Biol 48: 352-364.

Panchen AL. 1992. Classification, evolution and the nature of biology. Cambridge University Press, Cambridge, UK.

Park C, Zhang J. 2012. High expression hampers horizontal gene transfer. Genome Biol Evol 4: 523-532.

Pisani D, Cotton JA, McInerney JO. 2007. Supertrees disentangle the chimerical origin of eukaryotic genomes. $\mathrm{Mol}$ Biol Evol 24: 1752-1760.

Sapp J. 2009. The new foundations of evolution. Oxford University Press, Oxford.

Sogin ML. 1991. Early evolution and the origin of eukaryotes. Curr Opin Genet Dev 1: 457-463.

Stanier RY, van Niel CB. 1962. The concept of a bacterium. Arch Microbiol 42: 17-35.
Stanier RY, Doudoroff M, Adelberg E. 1963. The microbial world, 2nd ed. Prentice-Hall, Englewood Cliffs, NJ.

Wheelis ML, Kandler O, Woese CR. 1992. On the nature of global classification. Proc Natl Acad Sci 89: 2930-2934.

Wilkins JS. 2009. Species: A history of the idea. University of California Press, Berkeley, CA.

Wilson KL, Dawson SC. 2011. Functional evolution of nuclear structure. J Cell Biol 195: 171-181.

Winsor MP. 2006. Linnaeus's biology was not essentialist. Ann Mo Bot Gard 93: 2-7.

Woese CR. 1982. Archabacteria and cellular origins: An overview. In Archaebacteria: Proceedings of the 1st International Workshop on Archaebacteria (ed. Kandler O), pp. 3-17. Gustav Fischer, Stuttgart, Germany.

Woese C. 1998a. The universal ancestor. Proc Natl Acad Sci 95: $6854-6859$.

Woese CR. 1998b. Default taxonomy: Ernst Mayr's view of the microbial world. Proc Natl Acad Sci 95: 11043-11046.

Woese CR. 2004. A new biology for a new century. Microbiol Mol Biol Rev 68: 173-186.

Woese CR, Fox GE. 1977. Phylogenetic structure of the prokaryotic domains: The primary kingdoms. Proc Natl Acad Sci 74: 5088-5090. 


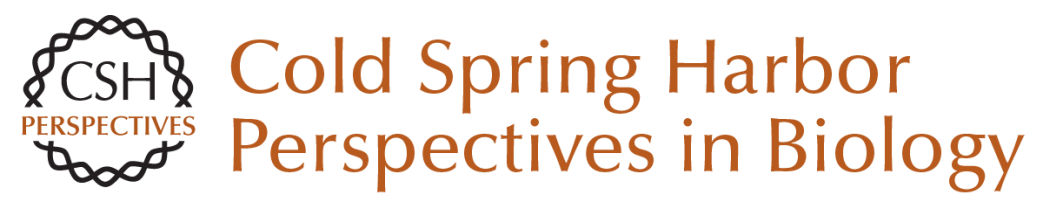

\title{
How Natural a Kind Is "Eukaryote?"
}

\author{
W. Ford Doolittle
}

Cold Spring Harb Perspect Biol 2014; doi: 10.1101/cshperspect.a015974

Subject Collection The Origin and Evolution of Eukaryotes

The Persistent Contributions of RNA to Eukaryotic Gen(om)e Architecture and Cellular Function Jürgen Brosius

Green Algae and the Origins of Multicellularity in the Plant Kingdom James G. Umen

The Archaeal Legacy of Eukaryotes: A Phylogenomic Perspective

Lionel Guy, Jimmy H. Saw and Thijs J.G. Ettema

Origin and Evolution of the Self-Organizing Cytoskeleton in the Network of Eukaryotic Organelles Gáspár Jékely

On the Age of Eukaryotes: Evaluating Evidence from Fossils and Molecular Clocks Laura Eme, Susan C. Sharpe, Matthew W. Brown, et al.

Origin of Spliceosomal Introns and Alternative Splicing Manuel Irimia and Scott William Roy

Protein and DNA Modifications: Evolutionary Imprints of Bacterial Biochemical Diversification and Geochemistry on the Provenance of Eukaryotic Epigenetics

L. Aravind, A. Maxwell Burroughs, Dapeng Zhang, et al.
Eukaryotic Origins: How and When Was the Mitochondrion Acquired?

Anthony M. Poole and Simonetta Gribaldo

Bacterial Influences on Animal Origins Rosanna A. Alegado and Nicole King

Missing Pieces of an Ancient Puzzle: Evolution of the Eukaryotic Membrane-Trafficking System Alexander Schlacht, Emily K. Herman, Mary J. Klute, et al.

The Neomuran Revolution and Phagotrophic Origin of Eukaryotes and Cilia in the Light of Intracellular Coevolution and a Revised Tree of Life

Thomas Cavalier-Smith

Protein Targeting and Transport as a Necessary

Consequence of Increased Cellular Complexity Maik S. Sommer and Enrico Schleiff

How Natural a Kind Is "Eukaryote?" W. Ford Doolittle

What Was the Real Contribution of Endosymbionts to the Eukaryotic Nucleus? Insights from Photosynthetic Eukaryotes David Moreira and Philippe Deschamps

For additional articles in this collection, see http://cshperspectives.cshlp.org/cgi/collection/

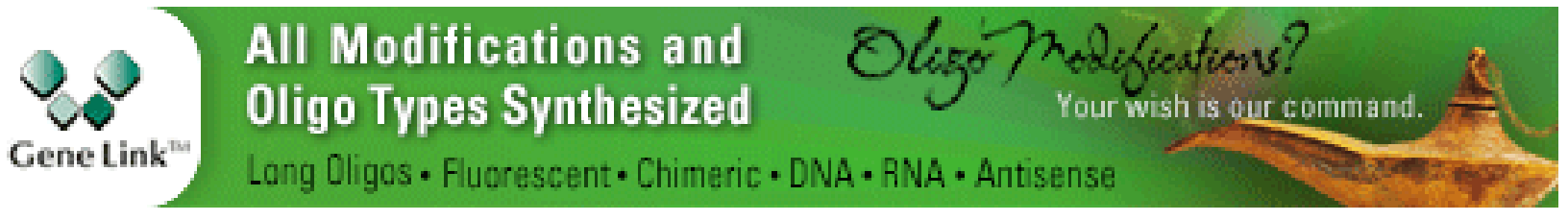


The Eukaryotic Tree of Life from a Global Phylogenomic Perspective Fabien Burki
Bioenergetic Constraints on the Evolution of Complex Life

Nick Lane

For additional articles in this collection, see http://cshperspectives.cshlp.org/cgi/collection/

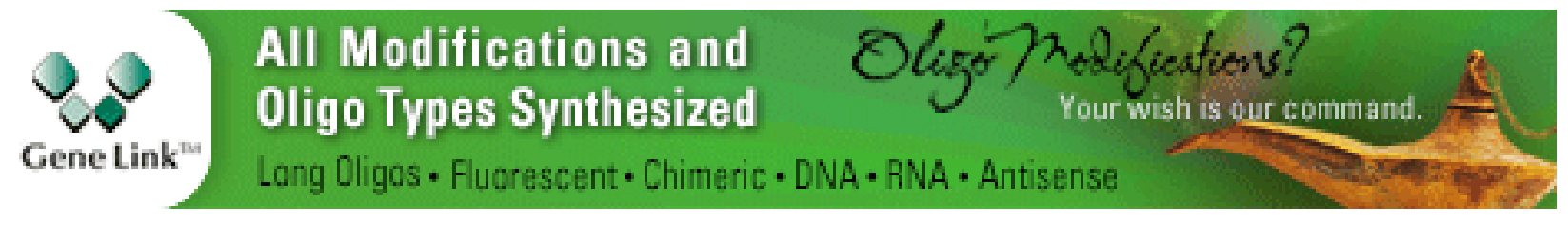

Copyright @ 2014 Cold Spring Harbor Laboratory Press; all rights reserved 